\title{
Web Quest Technologies for Learning English at University: Opportunities and Prospects
}

\author{
Oxana V. Khasanova* (a), Anna A. Karimova (b) Anastasiya M. Mubarakshina \\ (c) \\ (a), (b), (c) Kazan Federal University, 420008, Kazan (Russia), 18 Kremlyovskaya street, \\ khasanova_oxana@rambler.ru
}

\begin{abstract}
The emergence of new means of communication has led to the renewal of foreign language teaching technologies. First of all, it has made interactive project technologies popular, including web quest. By web quest, we understand the scenario of students' project activity on the topic under study using Internet resources, which involves group work of students.

The purpose of this work is to analyze the effectiveness of using this technology in English lessons at the Kazan Federal University. The method of research was a pedagogical experiment, as a result of which the authors identified the percentage of efficiency of mastering the material in English grammar through web quest technology in the experimental group and compared it with the indicators of the control group, where the experiment was not conducted.

It was found that, on average, students learned the lesson materials $27 \%$ more effectively than the students in the control group. In general, it is worth noting that the quest technology develops self-education skills by solving practical problems or problems that require the integration of knowledge from different subject areas. At the final stage, recommendations were formulated for organizing classes in English in the form of a web quest within the higher school. The possibility of using this technology in the study of other foreign languages was predicted.
\end{abstract}

Keywords: ELT, English, communication, modern technology, web quest.

(C) 2020 Oxana V. Khasanova, Anna A. Karimova, Anastasiya M. Mubarakshina

This is an open access article distributed under the terms of the Creative Commons Attribution License (CC BY 4.0), which permits unrestricted use, distribution, and reproduction in any medium, provided the original author and source are credited.

Published by Kazan federal university and peer-reviewed under responsibility of IFTE-2020

(VI

International Forum on Teacher Education)

\footnotetext{
* Corresponding author. E-mail: khasanova_oxana@rambler.ru
} 


\section{Introduction}

In the world of information, it is necessary to respond quickly to the demands of time, use non-standard solutions, be able to take autonomous actions and create innovations. Therefore, many countries are engaged in the modernization of the education system. It is known that the modern level of computer and telecommunications technologies opens up new opportunities for the development of adequate means of teaching foreign language culture in the organized teaching of foreign languages outside the language environment. The emergence of new means of communication has led to the updating of language learning technologies, first of all, made popular interactive project technologies, which include web quest. However, to date, there are no works that would contain methodological recommendations for the use of the web quest in teaching English in high school, which confirms the absolute relevance of the work.

\section{Purpose and objectives of the study}

The purpose of this work is to analyze the effectiveness of using WebQuest technology at English lessons at Kazan Federal University.

\section{Literature review}

To date, a vast array of information has been accumulated in the theory and practice of psychological and pedagogical research, revealing the scientific foundations and experience in shaping readiness of adolescents and young people for the family life. Currently, Russia is building a new education system focused on occurrence in world educational space. This process is accompanied by significant changes in pedagogical theory and practice of the educational process. Many methodologists and researchers pay attention to the integration of modern communication technologies in the educational process (Romaniukha \& Leshchenko, 2016). Special attention is paid to teaching English at Kazan Federal University, as well as creating an English-language communication environment (Guryanov, Rakhimova, \& Guzman, 2019). English is the intermediary language for all foreign students studying in Russia, so the motivation to study English is quite high (Kulikova, 2009). It is worth considering the theoretical study of web quest technology, the prospects of its practical application and the possibility of using information resources of the Internet and integrating them into educational process (Kuzmenko \& Valuyeva, 2019).

The developers of the web quest are Dodge (2001) and March (2004), professors at the University of California, San Diego. The technology is relatively new. The first web quests appeared in 1995, and in connection with the introduction of the Federal state educational system of General education received a "second birth" and are now one of the main means of forming students' communicative and ICT competencies. 
We understand web quest as a problematic task with role-playing elements. An educational Web quest is a site on the Internet that students use to complete a particular educational task (Hassanien, 2006). When creating and passing this type of technology, not only students is actively involved, but also the teacher (Manning \& Carpenter, 2008).

Web quest involves creating a problem task with elements of a role-playing game, which uses Internet resources to complete.

When working on a web quest, a number of competencies are developed:

- use of information technologies to solve professional tasks (to search for necessary information, design the results of work in the form of computer presentations, websites, flash videos, databases);

- self-learning and self-organization; team work (planning, distribution of functions, mutual assistance, mutual control);

- ability to find several ways to solve a problem situation, determine the most rational option, justify your choice;

- public speaking skills (mandatory pre-defense and defense of projects with presentations by authors, questions, discussions).

A web-quest can be subject-based (dedicated to solving a separate educational task within a subject or topic) or cross-subject (tasks from different subject areas are used in the same topic). There are also two types of web quests, depending on the timing of implementation:

- $\quad$ short-term (2-3 weeks);

- long-term (from 2-3 months to a year).

But it is not practical to use this technology for more than two months. Most of the work is done by students at home, and this significantly increases the educational load, because full participation in the web quest requires at least 4 hours per week. 
The developer of the web quest as a training task, Bernie Dodge (2011), defined the following types of tasks for web quests:

- retelling-indicates an understanding of the topic based on the presentation of materials from different sources in a different format. Result the work can be presented as a presentation, story, etc.;

- planning and design-involves the development of a plan or project based on specified conditions;

- self-knowledge-includes any means of exploring the personality, forcing the student to answer questions about themselves (moral problems, future plans, questions of self-improvement);

- compilation-converting information obtained from different sources into the final product. For example, in a book of recipes, a virtual exhibition;

- creative task - creative work in a specific genre (play, poem, song, video);

- analytical task-study the topic by analyzing the problem, exploring internal relationships, finding similarities and differences;

- detective, puzzle, mystery story - solving puzzles, solving riddles, mysteries;

- reaching a consensus - working out a solution to the problem;

- assessment-justification of a certain point of view;

- investigative journalism - reporting on an event that involves an objective presentation of information;

- scientific research-the study of various phenomena, discoveries, and facts based on unique sources.

A special feature of educational web quests is that part or all of the information for independent or group work of students with it is located on a specially created website. The teacher, depending on the level of students, provides them with links to Internet resources that contain all or part of the information on the topic being studied.

Web quest usually has a clear structure (introduction to the game situation, setting a problem question, role allocation, performing tasks within the role individually or in groups, evaluation, summing up) and its 
preparation goes through certain stages. Dodge (2011) highlights the following web quest structure: Introduction, Task, Process, Evaluation, Conclusion, Credits, and Teacher Page. However, this structure is not something frozen and is only used as the base, which can be changed if necessary. The teacher can design quest according to the level and needs of their students.

\section{Methodology}

The purpose of the research is to establish the effectiveness of web quest technology application in the process of formation of foreign language communicative competence of students of Kazan Federal University.

The hypothesis of the research is that the acquisition of lexical and grammatical material in English classes at the University will be faster and more effective if you organize classes on specific topics in the form of a web quest.

In this study, the following methods were used: review of theoretical literature, analysis of selected material, content analysis of Internet resources, development of tasks for the formative stage of the experiment. A pedagogical experiment that includes 3 stages: the ascertaining stage, the forming stage, and the control stage. Statistical analysis methods were used to calculate and interpret data.

\section{Results}

Based on the studied theoretical approaches of advanced teachers and psychologists to solving the problem of the development of foreign language speech of students in English lessons, an experimental study was conducted. The experiment took place between September and December 2019. The experiment involved 50 3rd-year students of Kazan Federal University, studying in the direction of "Teacher education (Russian and English)". Students were divided into 2 groups: a control group and an experimental group.

The pilot work included the following stages:

1. Ascertaining experiment. The goal is to identify the level of knowledge in grammar and the volume of thematic vocabulary of students in the control and experimental groups.

2. Formative experiment. The goal is to implement pedagogical conditions in the real educational process: organizing and conducting a web quest on the topic "Welcome to Kazan". 
3. Control section. The goal is to study the effectiveness of using the web quest in English classes in an experimental group.

At the preparatory stage, we had to prepare diagnostic tools that could give us an objective assessment of the development of speech of students of both groups, find out how broad the students ' knowledge in the field of tourism, travel and knowledge of the sights of Kazan is. Based on the complex nature of the diagnosis, we independently compiled 3 types of diagnostics aimed at identifying different indicators:

1) adequate understanding of English words on the topic;

2) the amount of vocabulary, the ability to select synonyms in a situation of foreign language communication;

3) the relevance of the use of vocabulary in specific communicative situations.

The data of the control and experimental groups at the ascertaining stage are presented in Figure 1.

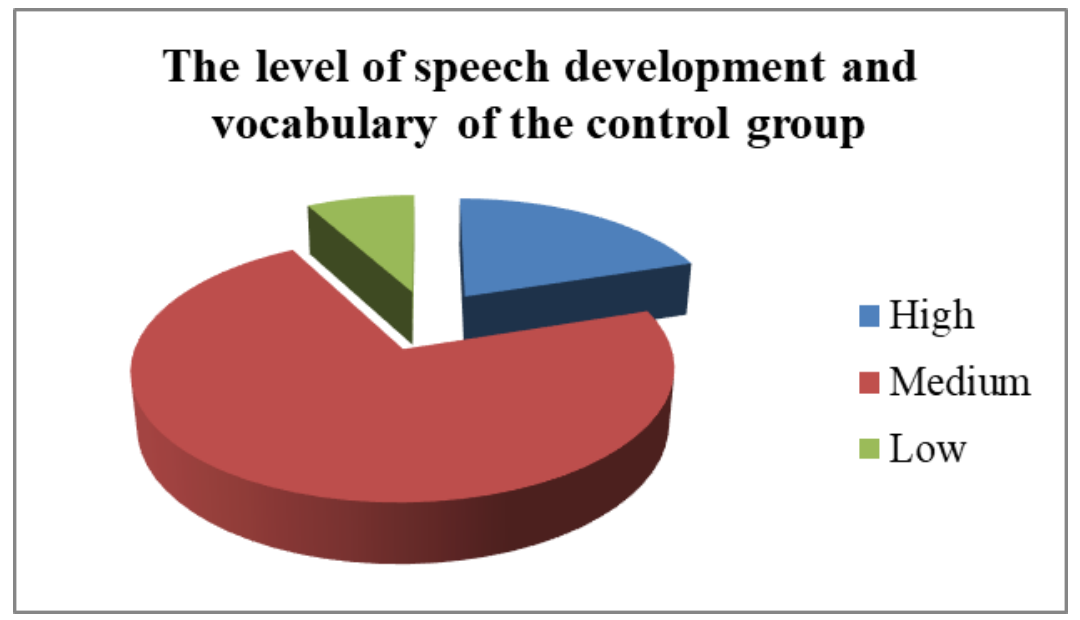

Figure 1. The level of speech development and the volume of vocabulary of control class at the ascertaining stage

It is worth noting that the indicators of the control class, as expected, have become higher than those of the experimental class. As can be seen from the data, in general, the class level is also average, but there are no students in the class with a high level of speech development, sufficient vocabulary and imagery of speech. Some students, having an average level of indicators, experienced problems with the selection of synonyms. In the form of a diagram, the numbers look like this. 


\section{The level of speech development and vocabulary of the e[perimental group}

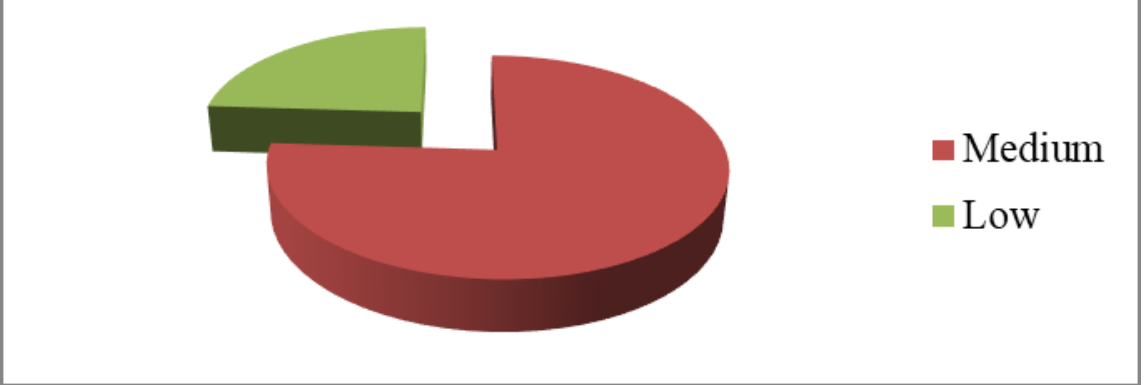

Figure 2. The level of speech development and the volume of vocabulary of experimental class at the ascertaining stage

Thus, the conducted ascertaining experiment allowed to reveal the level of speech development and the volume of lexical stock in the control and experimental groups and caused the need for a formative experiment in the experimental class.

At the stage of the formative experiment, we organized a web quest for the study of vocabulary and grammar "Welcome to Kazan". We chose a web quest with a puzzle task. Students had to find sights on the map of Kazan from photos. In addition, information about the attraction was given in English and dialogues between tourists and guides were staged. We chose this type of quest because a web quest based on a puzzle task requires synthesizing information from a set of sources and creating a puzzle that cannot be solved by simply searching for the answer on a specific Internet page. On the contrary, it is necessary to come up with a riddle, the solution of which requires:

- $\quad$ assimilation information from multiple sources;

- $\quad$ compiling information into a single whole through conclusions and generalizations from different sources of information;

- $\quad$ exceptions to complex traces that may initially appear to be correct answers to questions, but do not turn out to be correct on closer inspection.

It is worth noting that the theme for the quest was not chosen by chance. Many students studying at Kazan Federal University came from other cities and countries. Many of them have never been on a sightseeing tour of the city, so the quest "Welcome to Kazan" contributed not only to the assimilation of vocabulary and grammar on the topic, but also expanded the students ' linguistic and cultural knowledge. 
In the control class, additional work on speech development and familiarity with the quest was not carried out for the sake of the experiment's purity. Training was conducted with the use of other educational technologies.

According to the results of the formative experiment in both classes, even in the control class, where the work was not carried out, repeated testing was conducted for the same diagnostics. As a result, there were no significant changes in the control class, only a student with a low level moved to the middle level.

In the experimental class, the dynamics were quite clear. There were no students left in the class with a low level of speech development and insufficient vocabulary in the field of vocabulary on the topic "Travel and attractions", and all students who were at a low level rose to the middle level in working with synonyms.

You can compare the results obtained from the second test using Figure 3.

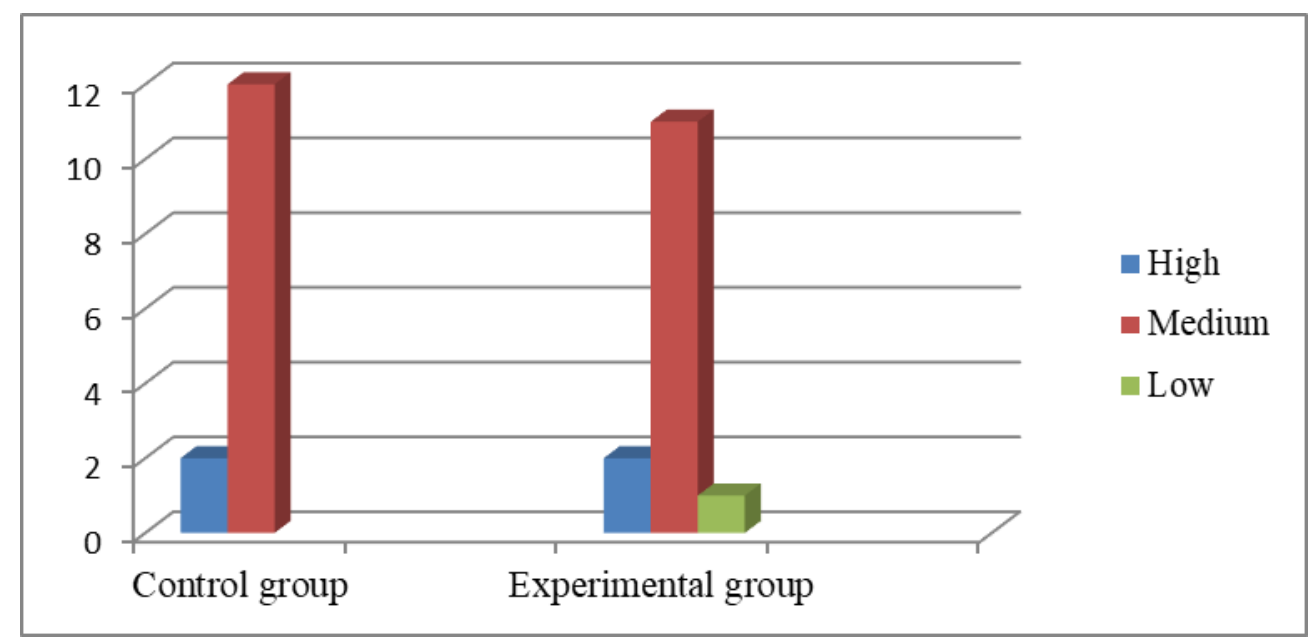

Figure 3. Comparative characteristics of the levels of speech development and the volume of lexicon of students in the control and experimental groups at the control stage

It was found that, on average, students learned the lesson material $27 \%$ more effectively than the students in the control group. A special positive effect of using web-quest technology in English lessons can be seen if compare the results of testing in the experimental group before and after the experiment. 


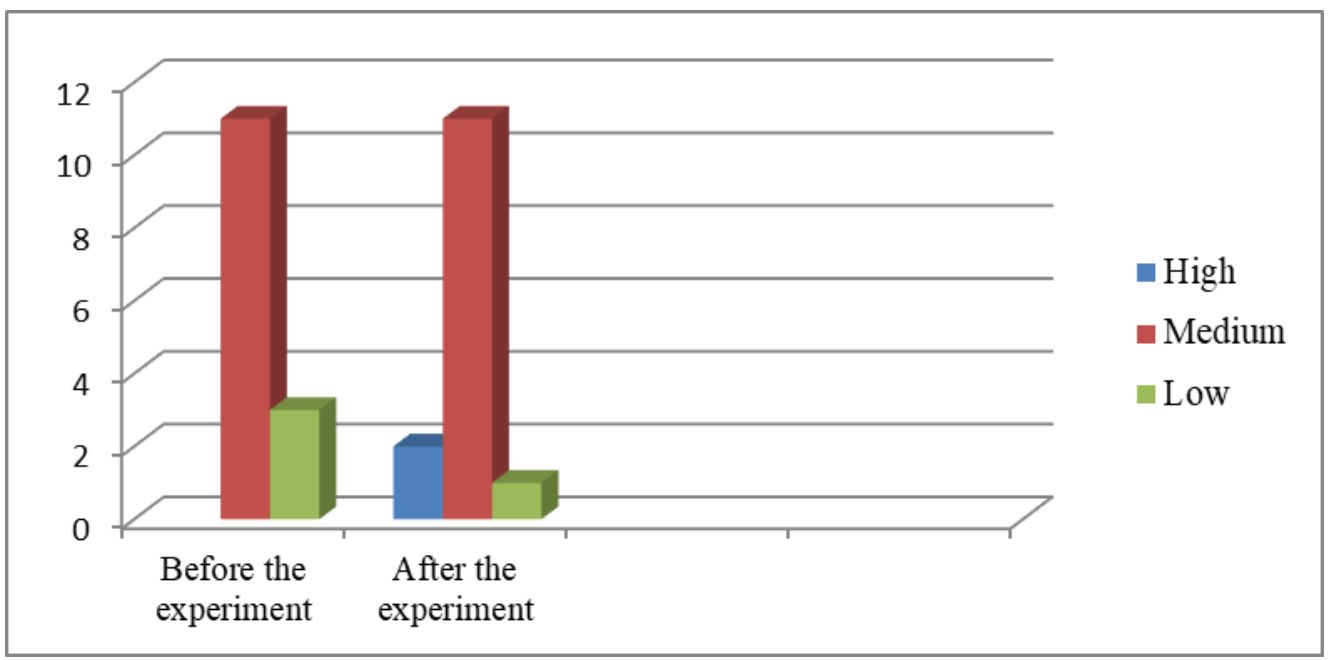

Figure 4. Comparative characteristics of the level of speech development and the volume of lexicon of students in the experimental group before and after the experiment

Data from the final stage of the experiment indicate that significant positive changes occurred in the level of speech development and the volume of lexical stock of students in the experimental class, due to the formative experiment conducted in the classroom with the use of a web quest.

\section{Discussions}

Web quests also help students develop the skills needed to a person of the 21 st century: the ability to navigate a huge flow of information, the ability to analyze, think independently and creatively, objectively evaluate their achievements, the ability to work in a team, keep up with the times (Sanford, TownsendRocchiccioli, Trimm, \& Jacobs, 2010).

The technology of web quests is focused on the effective formation of an integral system of universal knowledge, skills, as well as experience of independent activity and personal responsibility of students, i.e. the key abilities that determine the quality of modern education (Simina \& Hamel, 2005). It is aimed at maximum practical activity and is an actual mechanism for involving students in processes that contribute to the development of their information and communication skills. 
Despite the numerous advantages of this technology in learning English in higher education, there are many difficulties in using web quests in Russian universities:

- $\quad$ to complete the project students must have access to a Network and high speed Internet in each classroom;

- $\quad$ web quest technology requires students and teachers to have a certain level of computer literacy; slow Internet access may limit the type of resources that can be downloaded (for example, videos);

- $\quad$ many web quests that can be found on the Internet are created abroad, so they need to be adapted to specific training conditions.

Another omission may be the lack of reflection at the final stage. In this case, the relationship becomes oneway, and the results cannot be adjusted. In addition, if the technology is used for the first time, it is necessary to conduct preparatory work with parents at the preliminary stage, explaining to them the goals, tasks, and conditions of the educational project.

In the long term, this educational technology can achieve the following metasubject results: to develop students' ability to independently determine their learning goals and plan ways to achieve them, including alternative ones, to consciously choose the most effective ways to solve educational and cognitive tasks, to independently search and select the necessary information.

\section{Conclusion}

Thus, in the process of working on a web quest, the center of knowledge achievement is the student. The teacher ceases to be the main source of knowledge. It formulates tasks, searches for sources and links on the Internet, performs an Advisory role, and creates a learning environment in which learning takes place within the framework of a creative learning workshop. The use of this technology in working with students in English classes helps to create a stable interest in learning educational material and improving cognitive activity.

It was experimentally proved that students who studied vocabulary and grammar related to the topics "Travel" and "Sights of Kazan" by $27 \%$ mastered the material better, and performed tasks with great interest and enthusiasm. Learning, mastering and putting into practice the technology of Web-quest is extremely important because the use of information resources of the Internet and integrating them in the educational process contribute to the formation of key and subject competencies. The acquired competences encourage students to further self-development and self-education, which is the key to their further success outside the university. Thus, we consider the experiment completed, the research goal achieved, and the hypothesis proved. 


\section{Acknowledgements}

The work is performed according to the Russian Government Program of Competitive Growth of Kazan Federal University.

\section{References}

Dodge, B. (2001). Five Rules of Writing a Great WebQuest. Learning \&Leading with Technology, 28, 6-9.

Guryanov, I.O., Rakhimova, A.E., \& Guzman, M.C. (2019). Socio-Cultural Competence in Teaching Foreign Languages. International Journal of Higher Education, 8(7), 116-120.

Hassanien, A. (2006). Using Webquest to support learning with technology in higher education. Journal of Hospitality, Leisure, Sport and Tourism Education, 5(1), 41-49.

Kuzmenko, N., \& Valuyeva, N. (2019). The application of Web-quest technology at teaching philological disciplines. Proceedings of the 14th International Scientific Conference on Distance Learning in Applied Informatics DIVAI-2019, Latvia, 127-130.

Kulikova, O.V. (2009) Features of motivation for teaching foreign students. Problems of the humanities and natural sciences, 8, 229-232.

Manning, J. B., \& Carpenter, L. B. (2008). Assistive technology WebQuest: Improving learning for preservice teachers. TechTrends, 52(6), 47.

March, T. (2004). The learning power of WebQuests. Educational Leadership, 61(4), 42-47.

Romaniukha, M., \& Leshchenko, O. (2016). Personal learning environment in higher education. Proceedings of the 11th International Scientific Conference on Distance Learning in Applied Informatics DIVAI2016, Slovakia, 225-235.

Sanford, J., Townsend-Rocchiccioli, J., Trimm, D., \& Jacobs, M. (2010). The webquest: Constructing creative learning. The Journal of Continuing Education in Nursing, 41(10), 473-479.

Simina, V., \& Hamel, M. J. (2005). CASLA through a social constructivist perspective: WebQuest in project-driven language learning. ReCALL, 17(2), 217-228. 